\title{
Les Archives de la Planète. Fotografías y films pioneros del renovado Musée Albert Kahn. Bou- logne-Billancourt (Grand Paris)
}

\section{"Les Archives de la Planète". Photographs and films pioneers of the renovated Musée Albert Kahn. Boulogne-Billancourt (Grand París)}

\author{
Pilar Aumente Rivas \\ Profesora Emérita. Facultad Ciencias de la Infomación. Universidad Complutense de Madrid (España) \\ pilar_aumente@hotmail.com \\ Recibido: 07/06/2017 \\ Aceptado: $12 / 09 / 2017$
}

\section{Resumen}

La colección de fotografías y films pioneros reunida en los denominados Archives de la Planète, acoge unas 72.000 fotografías realizadas en placas de cristal autocromas, así como miles de metros de films realizados entre 1908 y 1932 a instancias del humanista y mecenas Albert Kahn, quien consciente de que la expansión de la cultura occidental y la imparable aportación de las nuevas tecnologías habrían de abocar a un cambio en el mundo, y convencido de que la falta de conocimiento de las culturas no propias era causa de numerosos enfrentamientos evitables entre los países, impulsó una serie de misiones fotográficas que registraran y dieran testimonio, para conocimiento contemporáneo y futuro, de las características específicas de las diversas culturas existentes. Para garantizar una mejor conservación y difusión de este gran legado cultural, el Departamento de Hauts de Seine (Gran París) ha abordado una renovación del Museo y Jardines Albert Kahn, incluyendo un nuevo pabellón de entrada y la actualización del resto de edificaciones que le constituyen.

Palabras clave

Archives de la Planète, Museo Albert Kahn, Distritos Culturales, Grand París, Hauts de Seine, Boulogne-Billancourt. 


\begin{abstract}
The collection of pioneering photographs and films gathered in the so-called Archives de la Planète, houses around 72,000 photographs taken on autochrome glass plates, as well as thousands of film meters made between 1908 and 1932 at the behest of the humanist and patron Albert Kahn, who was aware that the expansion of Western culture and the unstoppable contribution of the new technologies would lead to a change in the world convinced that lack of knowledge of non-native cultures, was the cause of numerous avoidable confrontations between countries, promoted a series of photographic missions that recorded and gave testimony, for the present and future knowledge, of the specific characteristics of the diverse existing cultures. To ensure better conservation and dissemination of this great cultural legacy, the Department of Hauts de Seine (Greater Paris) has undertaken a renovation of the Albert Kahn Museum and Gardens, including a new entrance pavilion and the updating of the rest of the buildings they constitute him.
\end{abstract}

\title{
Keywords
}

Archives de la Planète, Albert Kahn Museum, Cultural Districts, Grand Paris, Hauts de Seine, Boulogne-Billancourt.

Referencia normalizada: Aumente RIVAS, PILAR (2017): Les Archives de la Planète. Fotografías y films pioneros del renovado Musée Albert Kahn. Boulogne-Billancourt (Grand París)". Arte y Ciudad. Revista de Investigación, no 12 (octubre), págs. 59-86. Madrid. Grupo de Investigación Arte, Arquitectura y Comunicación en la Ciudad Contemporánea, Universidad Complutense de Madrid.

Sumario: 1. La colección fotográfica y fílmica de los Archives de la Planète. 1.1. La aparición de los autocromos. 1.2. Albert Kahn. La creación de los Archives de la Planète. 1.3. El proyecto científico y las misiones fotográficas. 2. El renovado museo del dominio departamental Albert Kahn. 2.1. La propuesta de Kengo Kuma. 2.2. Las casas japonesas y otras intervenciones. 2.3. La actualización del Musée Departamental Albert Kahn como factor de Distrito Cultural. 3. Bibliografía.

* Esta investigación se emmarca en el desarrollo del proyecto de Excelencia Plan Nacional de I+D (Convocatoria 2015) Distritos Culturales: Imágenes e Imaginarios en los procesos de revitalización de espacios urbanos. Referencia: HAR2015-66288-C4-2-P. Entidad: MINECO. Una primera aproximación a este tema fue presentada en el seno del I Congreso de Cine e Imagen Científicos realizado en la ciudad de Ronda en noviembre de 2016 y aparece en las Actas correspondientes. 


\section{La colección fotográfica y fílmica de los Archives de la PLanète.}

\subsection{La aparición de los autocromos.}

El pensamiento ilustrado impulsó el inicio de las ciencias experimentales, en especial de la química que se desarrolló de manera exponencial durante todo el siglo XIX. Ya en los primeros años del siglo empresas particulares, pequeñas y grandes industrias se lanzaron a la experimentación en busca de soluciones para la mejora de productos. La fotografía depende y evoluciona al calor de esa expansión química, al tiempo que se nutre de las aportaciones de la física y más específicamente de los logros de la óptica y la fisiología Es en el desarrollo de ese marco en el que hay que situar los trabajos de investigación de la empresa Lumière, especializada en fotografía, que en 1907, en los locales del Journal L'Illustration presentó a comercialización, con gran éxito en medios científicos y artísticos, la placa autocroma, para la obtención de la fotografía en color. No obtuvo, sin embargo, el respaldo necesario en los ámbitos financieros de repercusión industrial (Lavedrine y Gandolfo: 2009, 38) ${ }^{1}$, lo que condicionó su limitado desarrollo futuro, pese a las magníficas perspectivas abiertas.

Se conoce bastante bien el proceso de elaboración de estas "vistas" en color que vinieron a ser un producto de ayuda en la crisis que la gran empresa Lumière atravesó a partir de 1900. Los Cahiers d'Atelier conservados (periodo 1908-1929) dan suficientes referencias como para comprender suficientemente el proceso de las 11 operaciones específicas que permiten la creación de estas placas generalmente de $20 \times 84 \mathrm{~cm}$ (Ibidem, 176 y ss.).

En primer lugar, se procedía a efectuar una meticulosa selección de granos de fécula de patata, para lograr un calibre de entre 10 y 20 micras (por medio de

\footnotetext{
${ }^{1}$ En el periodo 1891 a 1895 los hermanos Lumière desarrollan una gran actividad experimental centrada en la obtención de placas tricromáticas de cristal. En 1903 solicitaron una patente denominada Procédé de photographie en couleurs. Es decir, aún no se asume la denominación de placa autocroma, necesitarían aún de cuatro años de perfeccionamiento para su puesta a punto a escala industrial, por lo que irán solicitando ampliaciones de la patente en sucesivos años (2 fueron presentadas en 1904, y otra en 1905). No obstante, las investigaciones para la obtención del color se rastrea mucho antes, sin recurrir a experiencias aurorales, hay que señalar que desde 1861 se venía experimentando en la fotografía en color. El procedimiento del escocés James Clerk Maxwell se conocía ya como el primer sistema de verdadera fotografía en color. Este procedimiento fue considerado complicado y dificultoso (Okuefuna: 2008, 321).
} 
la utilización de agua y la eliminación de los granos de mayor calibre. Con posterioridad, a estos granos se les sometía a un complejo procedimiento de teñido, y en un siguiente paso se efectuaba una mezcla de las féculas coloreadas, cuyo ajuste se realizaba de manera empírica. La siguiente operación es la aplicación del llamado primer barniz; a continuación llegaba el empolvado de varias capas (4), de carbón de madera, en pequeñas partículas. En un siguiente paso una laminadora aplanaba durante cinco minutos los granos de fécula con varillas cuidadosamente preparadas; posteriormente se procedía a la aplicación del segundo barniz y se añadía una emulsión compuesta por diversos productos a la que se incorporaban tres colorantes combinados en proporciones determinadas por Louis Lumière. Todas estas manipulaciones, junto a otras realizadas para la finalización comercial, son sumamente complejas y requerían del acompañamiento de conocimientos químicos aportados por colaboradores vinculados a la casa, este fue el caso de Alphonse Seyewetz, químico formado en Francia pero especializado en Alemania, en materias colorantes industriales, así como en otras materias de entre las utilizadas en los procedimientos de la autocromía. Vinculado a la empresa Lumière desde 1891 llegó a ser el jefe de los servicios de Química y se convirtió en una figura decisiva en el logro del proceso y en la creación del corpus teórico y práctico específico que supo sistematizar y difundir en publicaciones científicas.

Este procedimiento pionero para la obtención de fotografías en color marcó un hito en las investigaciones sobre este aspecto tan deseado, sin embargo, no supuso avance en otro de los retos a los que se enfrentaba la fotografía en la época, puesto que el valor de la placa autocroma está en la propia placa. No puede ofrecer la ventaja de la multiplicación de imágenes en papel, aspecto que era objeto de continuas búsquedas. Con el lanzamiento, a comienzos de los años 30, del filmcolor, la placa será sustituida por un soporte flexible que aprovechaba las investigaciones hechas en el campo del film.

\subsection{Albert Kahn. La creación de Les Archives de la Planète.}

Albert Kahn, importante banquero y mecenas asentado profesionalmente en Paris, pero radicado desde 1895 en una propiedad ubicada en Boulogne sur Seine, tuvo conocimiento de las investigaciones de la casa Lumière y se interesó por los sistemas de grabación de imagen en movimiento y de manera muy entusiasta por la aparición de la placa lograda para la obtención de ima- 
gen en color. Como consecuencia adquirió muy tempranamente, en el verano de 1908 (Okuefuna, 2008: 13), un primer lote de autocromos. Estas placas fueron destinadas a ser operadas por su chauffeur y compañero de viaje Alfred Duttertre que fue instruido para realizar estereoscopías, autocromas y algún film durante el viaje que Kahn² realizó alrededor del mundo, visitando Estados Unidos, Canadá, Japón y China. Parece ser que es durante ese viaje, cuando concibió su proyecto de crear los Archives de la Planète. Ante sus ojos, y gracias a esta nueva técnica fotográfica, se abría la posibilidad de conservar esas realidades culturales que tanto le fascinaban y que temía pudieran desaparecer debido a los cambios que se estaban imponiendo en todo el mundo como consecuencia de la industrialización. Por otro lado, la puesta en marcha de este proyecto abría, asimismo, la posibilidad de mostrar al mundo la realidad de las distintas culturas, contribuyendo con ello a su mejor conocimiento, potenciando así una buena relación "con" y "entre" ellas. Es decir, comprendió la importancia de utilizar los autocromos y films para ahondar y difundir el conocimiento; no obstante, hay que introducir un matiz, su público objetivo directo e immediato eran las élites, no la sociedad en general, aunque la transformación de esta estuviera en su objetivo final. Se trataba de que quienes hubieran de estar en los núcleos de decisión tomaran conciencia de la pluralidad y pudiera establecerse una atmósfera de respeto basada en el conocimiento de las singularidades de los pueblos.

De los muchos proyectos que impulsó A. Kahn, este es el que mayor capacidad de difusión y futuro tenía. Enlazaba con las Bourse Autour du Monde creadas por él en la primavera de 1898 (Journal Le Temps) para financiar el viaje de ampliación de conocimiento de los futuros profesores y periodistas, (que tenían en sus horizontes la formación de la sociedad), quienes "manteniendo los ojos bien abiertos", pudieran llegar a conocer las distintas culturas del mundo. Las bolsas de viaje fueron gestionadas por la Universidad de París, para llevar a la superación, a través del conocimiento directo de la diversidad, a los mejores alumnos, entre los que finalizaban sus estudios superiores. Las bourses conllevaban para el becado la obligación de establecer un recorrido pactado, portar una cámara "Kodak-poquet" ( Coeuré, 1996: 142-3) para documentar visual-

\footnotetext{
${ }^{2}$ También se le instruyó para hacer registros sonoros, aunque parece ser que un accidente en el transporte, durante los primeros momentos del viaje, inutilizó los cilindros de cera para el registro. A partir de esa circunstancia, se renunció a utilizar ese recurso.
} 
mente el recorrido, tener al corriente de los avatares del viaje a la universidad, y elaborar un informe al finalizar los 15 meses de viaje que se financiaban; por último, los beneficiarios de las becas se comprometían -no solo a conocer, sino a difundir-, es decir, se obligaba a compartir ese conocimiento, puesto que un requisito importante a cumplir era el compromiso de pronunciar conferencias que transmitieran los conocimientos adquiridos durante el viaje.

Con todo el material recopilado por las Bourses, y el de otras iniciativas que mencionaremos, se constituyen los Archives que no solo están compuestos de la colección que se conserva en su sede de Boulogne-Billancourt, el fondo de los 72.000 autocrómos, sino que además integra 183.000 metros de imágenes fílmicas conservadas en el servicio de les Archives du film en Bois d'Arcy. Respecto a la documentación añadida a las imágenes que se conservan en los $A r-$ chives, hay que recordar alguno de los avatares sufridos a lo largo del tiempo, mencionando, al menos, que parte de los cartones que acompañaban a las imágenes fue requisada por las fuerzas alemanas en 1940, y felizmente recuperada por la Armada Rusa (Coeuré, 1996: 143).

El proyecto de Les Archives de la Planète, además de su entidad propia, complementaba, superándola, la ambición docente de las Bourses y enlazaba asimismo con otras plataformas creadas y animadas por el propio A. Kahn. En efecto, la Societé Autor du Monde en 1906 (1906-1949), recogía la actividad que los becarios venían realizando al reunirse periódicamente desde 1902 en cenas que servían para deliberar sobre los conocimientos obtenidos en los viajes. Al crearse formalmente la Sociedad, -en un acto presenciado por grandes personalidades de la política y la cultura-, el círculo se abrió pero mantuvo su sede en la propiedad de Kahn en Boulogne Billancourt, en una mansión que será conocida como Le Cercle, de ahí que con frecuencia se hable del Circulo de A. Kahn o del Círculo Autour du Monde. El Círculo mantuvo estrechas relaciones con la Commission Internationale de Coopération Intellectuelle (CICI) (Liga de las Naciones), antecedente de la UNESCO, siendo su enlace el filósofo Henri Bergson, antiguo amigo de Kahn. La finalidad del Circulo era «travailler à répandre, en France, la connaissance exacte des pays étrangers, à l'étranger celle de la France, à faire comprendre et estimer tout ce que l'on peut appeler la civilisation internationale ${ }^{3}$; respondía al espiritu internacionalista que Kahn insuflaba

\footnotetext{
${ }^{3}$ http://albert-kahn.hauts-de-seine.fr/albert-kahn/fondations/
} 
al conjunto de su obra. El Círculo podía, y así lo hizo, invitar a todo tipo de personas, personalidades (Bergson, Madame Curie, Einstein...) o no, que compartieran sus objetivos. En esas sesiones las fotografías y los films de los Archives de la Planète jugaron un papel didáctico crucial.

\subsection{El proyecto científico y las misiones fotográficas.}

El planteamiento científico de los proyectos de A. Kahn se estructuraba en torno a la acción reguladora del Comité Científico formado por Henri Bergson y Emmanuel de Margerie, y se consolidó a través del impulso metodológico de J. Brunhes, geógrafo imbuido de un cristianismo social (Brunhes, 1993: 16) que animó sus orientaciones. Se formó como geógrafo en la École Normal Superieure de París, seguidor de Vidal de la Blache ${ }^{4}$, junto con Jules Sion, Albert Demangeon y Emmanuel de Martone, en 1910 publicó un volumen dedicado a la Geografía Humana, texto fundacional de la nueva ciencia que al tener entre sus objetivos el estudio de las poblaciones en sus medios, coincidía perfectamente con los objetivos culturales de A. Kahn. De esta manera, al ofrecerle la dirección científica de sus proyectos, tras dotarle una cátedra en el Collège de France, Brunhes implantó una metodología de organización en los Archives que será seguida, quizá no en los altos niveles de precisión que se exigía, pero sí de manera aceptable ${ }^{5}$. Para ello se instruyó a los fotógrafos colaboradores.

Desde el momento en que asume la dirección científica, toda acción de los operadores debe responder a un plan estructurado o, si las circunstancias lo requerían, una inmediata respuesta con un conocimiento de la situación y un "control" por parte de la dirección y del Comité. Brunhes elevaba ante este la propuesta de planificación de una nueva misión; una vez aceptada, establecía una serie de reuniones previas preparatorias de cada misión, en lo que se ha dado en llamar "curso acelerado de Geografía Humana" dedicado al país o paí-

\footnotetext{
${ }^{4}$ Vidal de la Blache fue profesor de la École Normale de París. Fomentó el estudio de las regiones entendiendo las relaciones hombre-medio. Partía de la afirmación de que la naturaleza ofrece unas potencialidades a los hombres que habitan la zona, lo que favorece que se cree un género de vida en función de las relaciones establecidas con el medio ambiente. Por ello defendía que la geografía ha de estudiar las regiones para así llegar a conocer y comprender los géneros de vida.

${ }^{5}$ Es quizá en los autocromos de los primeros viajes en los que se advierte la falta de algún dato, relativo, por ejemplo a la hora, sin embargo, la ubicación está bien referenciada.
} 
ses que se visitaba en cada una de ellas, apoyado en documentación, mapas precisos para la época (cartes d'état-major), escritos de referencia etc. (Castro, 2008).

Brunhes ya había introducido en su tesis aspectos diferentes de la Geografía Humana que le llevaban a distinguir dos sectores de carácter general que le indicaban el valor de dos tipos de documentos: documentos de orden geográfico y documentos relativos a los movimientos sociales y políticos. Esa clasificación que habrá de aplicarse a la organización general de los Archives, derivaba de la estructuración en que se dividía los diferentes estadios de la nueva ciencia:

- Geografía de las necesidades vitales: comer, vestir, dormir (la casa como elemento esencial)

- Geografía de la explotación de la tierra: la necesidad de superación de la situación de recolección, caza, pesca que lleva, en una fase siguiente a trabajar la tierra, domesticar animales y explotar minas y canteras.

Estos dos niveles estructuran una primera sección temática de imágenes en el extranjero: "entorno" y "hábitat", en la que se recogen las imágenes relativas a los paisajes, las casas, los monumentos y todo tipo de arquitectura. Por otro lado, se agrupan las imágenes de la vida cotidiana, la agricultura, los medios de locomoción o de transporte.

Otros dos niveles complementan la globalidad de la Geografía Humana:

- Geografia económica y social. El hombre vive en grupo (familia, sociedades), división del suelo, normativas y legislaciones.

- Geografía política y geografía de la historia: fundación de los Estados.

A estos dos estratos les corresponden las imágenes de los fenómenos sociales: religión, fiestas diversas, bodas y enterramientos, las artes, los hombres célebres y escenas de la vida militar, tanto en Francia como en el extranjero.

Para poder llevar a cabo estas clasificaciones era preciso que las imágenes estuvieran perfectamente identificadas, para lo cual se instruye a los fotógrafos en un método sistemático de identificación, en el que se han de seguir los siguientes estandares mínimos en la ficha de cada imagen, sean imágenes de fotografía convencional, autocromos o films: 
- Fecha: día, mes, hora (si es el caso, por ejemplo: puestas de sol).

- Lugar: nombre del pueblo, región, etc.

- Tema: pequeña explicación del interés de la imagen tomada, «incluso si vuestra interpretación es considerada más tarde como inexacta, será muy útil que hayáis anotado vuestra impresión primera» (Castro, 2008).

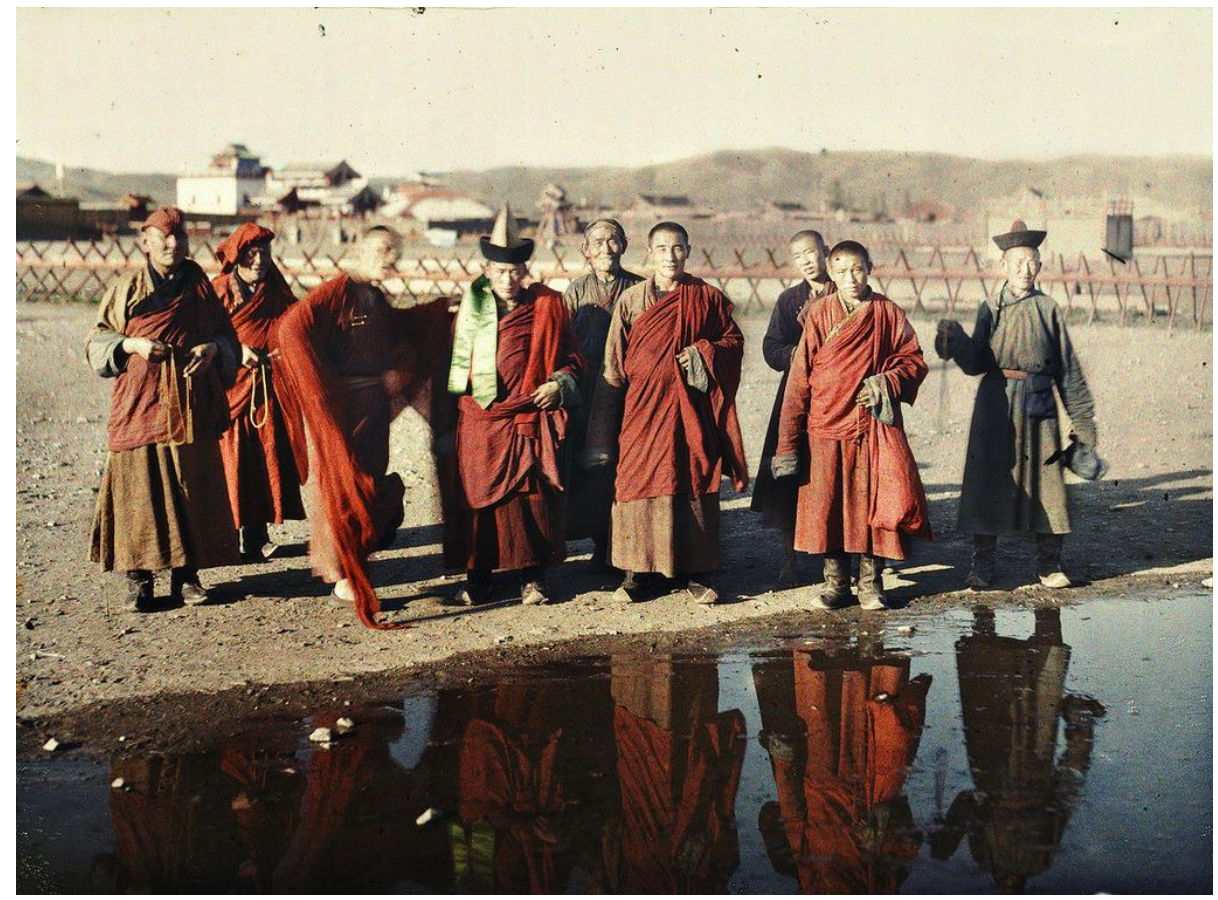

Fig.1. S. Passet. Lamas del Palacio Amarillo. 1913.

https://es.wikipedia.org/wiki/Albert_Kahn_(banquero)\#/media/File:1913_Lama_of_ Yellow_Palace_in_Khuree.jpg (\&Public Domain)

Teniendo esto en cuenta, y según las agrupaciones temáticas se daría cuenta visual de la arquitectura, de los caminos, es decir, de la ocupación improductiva de los suelos; en segundo lugar, de los datos de la realidad vegetal y animal de la zona: animales domésticos, campos de cultivo o no, jardines etc... En último lugar, de un tercer grupo de hechos, los relativos a la economía destructiva, por ejemplo las devastaciones vegetales o las explotaciones minerales. En cualquier caso, los testimonios aportados van mucho más allá, son un documento de gran interés para el conocimiento del 
periodo recogido. Es cierto que su pretensión enciclopédica, queda en algunos aspectos con algunos vacios, pero su vocación globalizadora nos sigue deslumbrando hoy.

En 1912 comenzaron las misiones bajo la supervisión de Brunhes, sin embargo, la recopilación de imágenes la había puesto en marcha el propio Albert Kahn directamente; habían visitado ya varios departamentos franceses y más de veinte países antes de la incorporación del geógrafo. El periodo sistemático de las misiones abarca de 1912 a 1933, a lo largo del cual la documentación gráfica de cincuenta países es el corazón de un estudio sistemático (Castro, 2008).

A partir de esa fecha, la situación económica de A. Kahn sufre las consecuencias de la crisis de 1929 y en 1936 se ve en la circunstancia de tener que vender su finca, jardines y archivos, que son adquiridos por el Departamento de la Seine. Desde ese momento los Archives permanecen cerrados, sin embargo, los jardines son abiertos al público. Será en la decáda de los '70, cuando, ante una nueva conciencia del valor del patrimonio, se dote un equipo de conservadores para los Archives (1974). A partir de ese momento se invierte en restauración y conservación; en los últimos años se ha digitalizado el 10\% de la colección, de tal manera que se ha puesto a disposición del público en general, a través de la web creada, un repertorio de imágenes que permite vislumbrar el gran interés de este patrimonio.

La colección de los Archives de la Planète, se compone no sólo de las fotografías estereoscópicas, autocromos y films que A. Kanh encargó realizar a fotografos y amateurs ${ }^{6}$, sino que también forman parte del mismo fotografias que él compró a viajeros y fotógrafos independientes que habían coincidido con él en sus objetivos o su enfoque. Supo rodearse de buenos aficionados y profesionales; entre los nombres que destacan, hay que mencionar, en primer lugar, a su fiel chauffeur y primer encargado de tomar las instantáneas de su viaje alrededor del mundo, Alfred Dutertre. El primer fotógrafo profesional que colaboró con los Archives fue Auguste Léon, quien inició su trabajo para Albert Kahn en 1909; otros fotógrafos, viajeros y aficionados fueron Camille Sauvageot, Paul Castelnau, Léon Busy, Stéphane Passet, Jules Gervais-

\footnotetext{
${ }^{6}$ Se contabilizan en torno a 4.000 obras estereoscópicas en blanco y negro.
} 
Courtellemont, Roger Dumas, Georges Chevalier 7, Fredéric Gadmer, Fernand Cuville, Lucien Le Saint, Marguerite Mespoulet. El propio Bruhnes participó en algunas misiones: Italia, los Balcanes, España, Siria, Libano, Canada, así como en algunas visitas realizadas en el interior de Francia ${ }^{8}$.

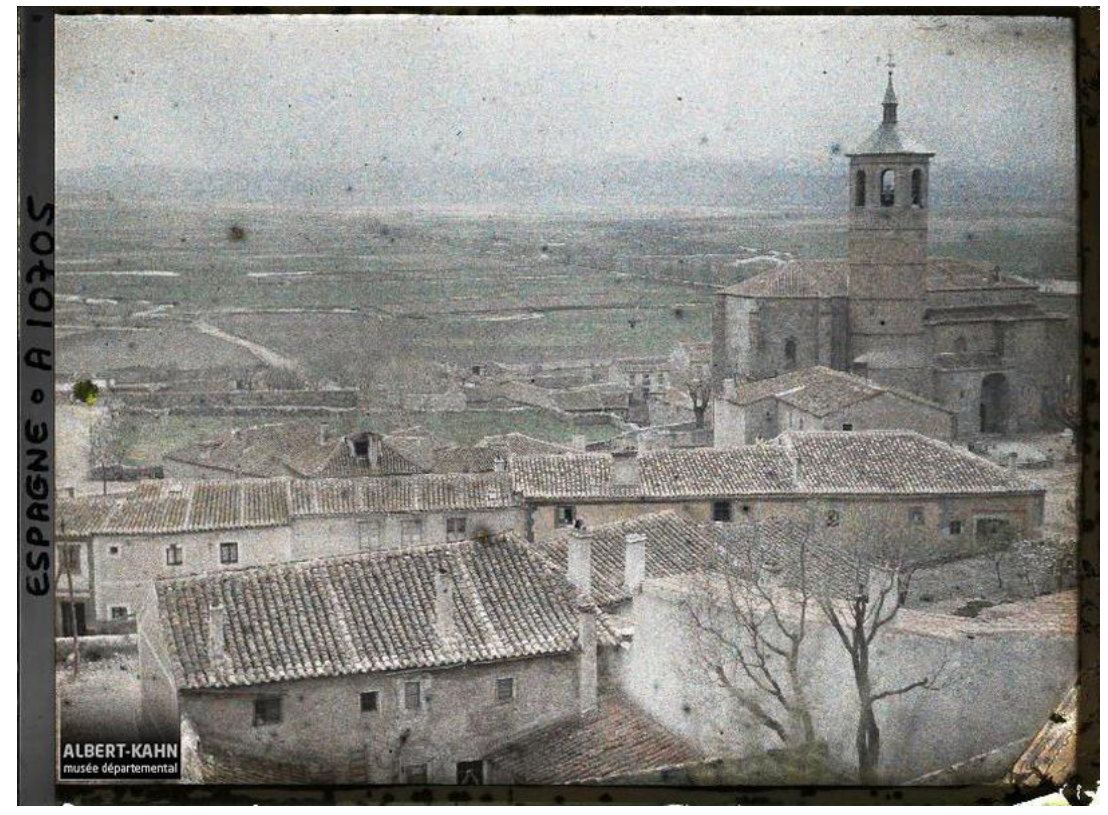

Fig. 2. Chevalier. Avila. Panorama hacia el sur. Campos de trigo. 1917. Fuente: http://collections.albert-kahn.hauts-de-seine.fr/ ?page=themes\&sub=paysages (®Public Domain)

España fue objetivo de misiones de estudio. La más estructurada fue la de la primavera de 1917 (abril-mayo), en la que efectivamente participó Bruhnes en compañía del fotógrafo Georges Chevalier. Su recorrido fundamentalmente se desplegó en el centro y norte del país. De Aranjuez hacia el norte, visitando ciudades y zonas rurales de Castilla: Avila, Burgos, Segovia; León (As-

\footnotetext{
${ }^{7}$ Discípulo de August Léon, trabajó para Kahn desde 1913, fue un hombre clave en la preservación de la colección de Les Archives, que supo custodiar a partir de la ruina de Kahn; de hecho, en 1936 fue nombrado por el Departamento de la Seine nuevo propietario del legado, responsable oficial de la colección. Con posterioridad se le valorará tambien por su obra dedicada a la Exposición Universal de 1937.

${ }^{8}$ http://albert-kahn.hauts-de-seine.fr/archives-de-la-planete/les-collaborateurs/jean-brunhes/
} 
torga); La Rioja; Pais Vasco, Asturias (Oviedo), Galicia (Coruña, Santiago), recogiendo imágenes alusivas al entorno geográfico físico, pero también al uso de la tierra, al hábitat, a la forma de vestir, las características físicas de los seres humanos de la zona, retratos a determinados personajes populares individualizados, así como a grupos (grupos de muchachitos, mujeres, grupos sociales de identidad étnica, etc.) respondiendo a una mirada sistemática. Con este recorrido se complementaba el realizado por Auguste Léon en la misión desarrollada en 1914 que había revisado fundamentalmente desde el centro hacia el sur: Toledo, Córdoba, Sevilla, Granada... El acopio de imágenes es muy notable y constituye reservorio denso para el estudio de la España de la época, a pesar de sus indiscutibles lagunas.

El concepto de Mission de carácter fotográfico, con vocación de recoger las imágenes de los elementos a los que se otorga valor de pervivencia, con afán de realizar un archivo de los documente a futuro, nos remite al origen de la misma creación de los archivos sistemáticos para bienes culturales que se arma conceptualmente en la herencia ilustrada, en los comienzos del siglo XIX, casi en paralelo al nacimiento de la propia fotografía ${ }^{9}$, apreciando desde muy temprano los aspectos positivos que aportaba la fotografía para este menester, pero será la Mission Helliographique de 1851 la que otorgue el modelo. Para llevar a cabo la catalogación de monumentos y arquitecturas religiosas, castillos teatros etc., de Francia se seleccionó a 5 fotógrafos de la Societè Helliographique recientemente creada. De los cinco (Le Gray, Mestral, Bayard, Baldús y Le Secq) algunos estuvieron muy vinculados al arte pictórico, como Baldús y el propio Le Secq, quien simultaneó sin ambajes la pintura con su actividad fotográfica. Ya antes del encargo de la Mission, Le Secq había publicado su extenso Álbum dedicado a la Catedral de Chartres; con él diseñó un paradigma que muchos seguirán a lo largo del tiempo y que tuvo gran difusión. Su huella se verá en las tomas de imagen de las fotografías de arquitectura, fundamentalmente de la religiosa, tanto para exteriores como para los interiores, tomas que hasta entonces se habían evitado por sus dificultades técnicas.

La huella de Le Secq se aprecia en los encuadres y la estética de muchas de las imágenes de las misiones de Albert Kahn. El antecedente encajaba perfec-

\footnotetext{
${ }_{9}$ Para estas etapas aurorales de la fotografía de arquitectura y de la creación de archivos fotográficos culturales véase (Aumente, 2011: 21 y ss).
} 
tamente en el espíritu del proyecto del mecenas y, aunque de visión y objetivos más amplios, suponía una base sobre la que hacer crecer el suyo. No es posible obviar la referencia.

Todo ello nos lleva a destacar la actitud que impulsó la creación de Les Archives como respuesta a un posicionamiento remotamente anclado en la concep-

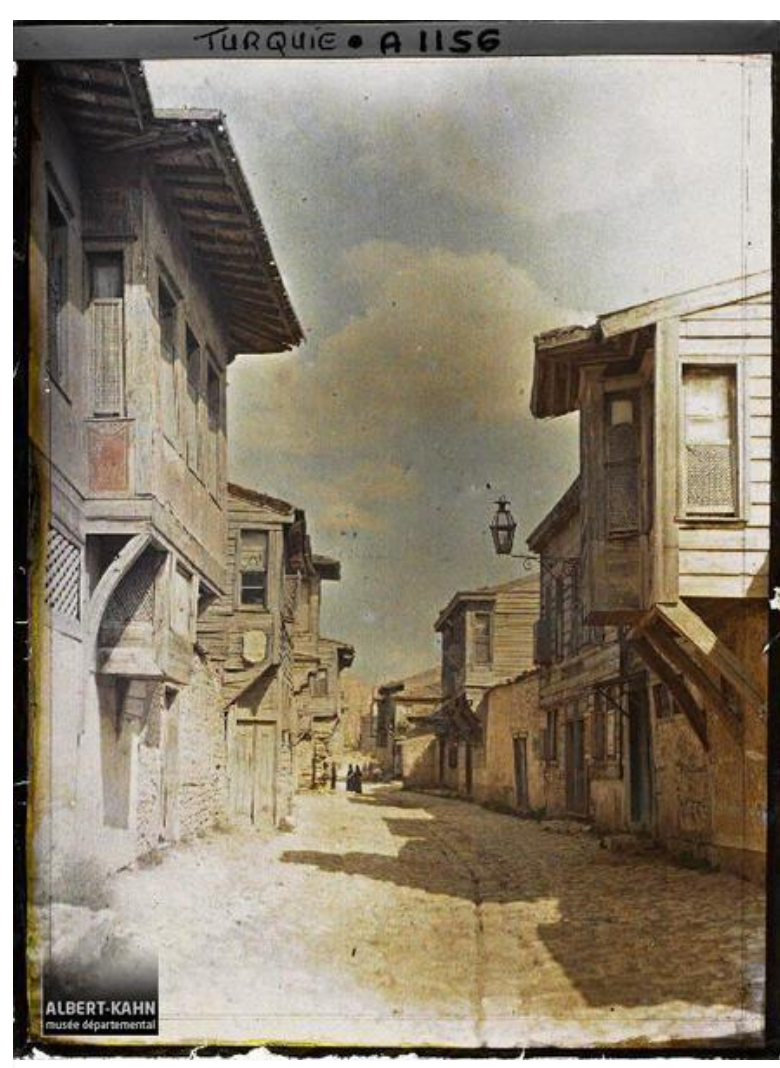

Fig. 3. S. Passet. Misión Passet en Turquía: calle empedrada de Estambul. Construcciones elevadas en madera sobre base de piedra. 1912. http://collections.albert-kahn.hauts-de-seine.fr/

(® Public Domain) ción positivista del pensamiento por parte de Albert Kahn, como es la aplicación directa de la valoración del concepto de experiencia que está en el centro de la teoría de Comte. La misma utilización de autocromos incide en la voluntad de fidelidad a la realidad, puesto que el color añade un plus de cercanía y verosimilitud, a pesar de la estetización que supone el parecido mayor con las pinturas de la época, en las que el color dominando en importancia al dibujo, asimilaba las fotografías a los cuadros ${ }^{10}$. Las fotografías y los films son por otro lado, y a consecuencia de ello, una gran fuente para la comprensión de la historia de las variantes culturales del primer tercio del siglo $\mathrm{XX}$, aunque sus fundamentos teóricos tienen sus raíces en la teo-

\footnotetext{
${ }^{10}$ La relación pintura y fotografía era muy fuerte en aquel periodo. En Francia la huella del impresionismo y del divisionismo, que ya habían sido superados en el interés de los artistas, comenzaban a ser valoradas por el público. No hay que olvidar que en el caso del neoimpresionismo, o puntillismo, el fundamento teórico es coincidente con el que sostenía la teoría del autocromo, la teoría aditiva del color (síntesis aditiva).
} 
ría que dominó la segunda mitad del siglo XIX (aunque fuera elaborada en la primera mitad). Son producto del desarrollo del giro hacia lo cotidiano que sufrió el concepto de hecho histórico, que basculó desde el gran acontecimiento político, hacia lo diario y supuestamente banal. En el caso de Les Archives encontramos los dos enfoques, puesto que se cubren grandes acontecimientos políticos (por ejemplo en Francia), pero la mayoría de las imágenes están dedicadas a la vida cotidiana de las distintas culturas; e incluso en la numerosa dedicación a los hechos en relación con la Primera Guerra Mundial, son con frecuencia las situaciones no bélicas las que se recogen, las cotidianas de los soldados o de los pueblos y ciudades -a veces devastadas- ellas son las que aparecen reflejadas.

Hay que introducir matices a este planteamiento, las imágenes son realizadas con una mirada que no podemos llamar estrictamente objetiva, aunque pretenda parecerlo, sino una mirada que se dirige a expresar el deseo de interesarnos por lo que la imagen nos propone. Si hay construcción de realidad, no hay que olvidar que esa elaboración para una mejor aprehensión de lo real ya se dio en Italia entre los fotógrafos de escenas urbanas, como los Alinari con un carácter efectista (colocación de las personas y los grupos, forzado de perspectivas al estilo renacentista, etc...) Mucho más natural -aunque exista preparación y colocación o búsqueda de encuadre- resultan las imágenes de Les Archives. Junto a ello, se debe poner de relieve el interés que la colección tiene para la historia, no solo política o social, sino para el propio devenir del cine $^{11}$. Ha de evidenciarse, igualmente, la coherencia de los proyectos y la circularidad del planteamiento.

Del estudio de las distintas plataformas culturales que pone en marcha Albert Kahn se desprende que se desarrollan en torno a una serie de objetivos: educar a las élites, conocer los pueblos del planeta, lograr el entendimiento entre los pueblos, actuar sobre el mundo: diseñar una mejor organización del planeta, conseguir la paz mundial. La metodología utilizada es de carácter mixto: puesta a punto de los nuevos métodos de análisis y conocimiento de la

\footnotetext{
11 «En effet, si les ADLP constituent une admirable source pour l'histoire tout court, elles ne le sont pas moins pour celle du cinéma et des formes filmiques. Les ADLP documentent certes, un monde «dont la disparition fatale n'est plus qu'une question de temps»; mais elles nous donnent aussi à voir un genre -le cinéma «documentaire»- en train de s'expérimenter... On est loin d'une quelconque évolution linéaire: les films des ADLP glissent d'un genre à l'autre en défiant la catégorisation» (Castro, 2008).
} 
realidad partiendo de un positivismo matizado, en cuanto al valor dado a la experiencia directa, nuevos planteamientos pedagógicos y método científico de la recien creada Geografía Humana.

Para desarrollar los proyectos pone en juego diferentes instrumentos: viajes, bolsas de viaje, conferencias, informes, publicaciones, etc., y las nuevas tecnologías de la época, tanto fotografía convencional (estereoscopias) como experimental (autocromos), films; desarrollo de Misiones; acciones de fotógrafos y cameramans, que llegan todos ellos en sí mismos a erigirse en punto de interés preferente en la concepción general del proyecto. En definitiva, el fondo de la colección no puede desvincularse del global de la red cultural en que se disemina el proyecto y a su vez es un punto nodal del mismo. Un proyecto que analizado en el momento actual adquiere un interés multiplicado puesto que responde a una valoración de la experiencia, y a la voluntad de promoción del conocimiento, e impulsa la difusión del mismo poniendo a la imagen como vehículo privilegiado en el proceso, sin dejar de tener en cuenta el reconocimiento y apoyo hacia la importancia de los aspectos históricopedagógicos. Desde la actual sociedad del conocimiento ha de estimarse un legado marcado por el respeto y la valoración de la diferencia.

\section{El renovado Museo del dominio departamental Albert Kahn.}

\subsection{La propuesta de Kengo Kuma.}

El dominio Albert Kahn ha sido reconocido como Museo de Francia y el Estado le ha inscrito en la relación de Monumentos Históricos. De cara a la presentación actualizada que merece, y en orden a la mejor conservación de sus valores patrimoniales, el Departamento de Hauts de Seine, teniendo en cuenta las felices relaciones que mantuvo Albert Kahn con Japón y las actuales potencialidades que las firmas y los visitantes japoneses suponen para la economía de Hauts de Seine, ha puesto en marcha la materialización del proyecto elevado por el arquitecto japonés Kengo Kuma que supone la construcción de un edificio de acogida de $2.300 \mathrm{~m}^{2}$ y la rehabilitación de las edificaciones ya construidas, incluyendo alguno de los pabellones del jardin (el Palmarium).

En el proyecto del edificio en construcción el arquitecto juega con la revitalización del espacio engawua (porche o galería) de la cultura japonesa, espacio que sorprendentemente le falta a una de las casas japonesas del patrimonio 
del museo. Un espacio a medio camino entre el espacio exterior y el interior ${ }^{12}$. Espacio relacional, perfectamente coherente en un edificio de acogida para un museo. Espacio que en Japón es ofrecido por la naturaleza, mientras para Kuma, en occidente, ese espacio intermedio vendría dado por la propia arquitectura. Diseñado en dos alturas en el edificio que se está terminando de construir, la primera ha de acoger exposiciones temporales y una tienda, en el segundo nivel, orientado hacia los jardines -por tanto al interior del conjunto- se han previsto paneles vidriados que permitan apreciar tan bella perspectiva. El cierre con paneles y listones colgantes de madera permitirá la gradación de la luz. Las grandes vidrieras abrirán la librería hacia el paisaje vegetal.

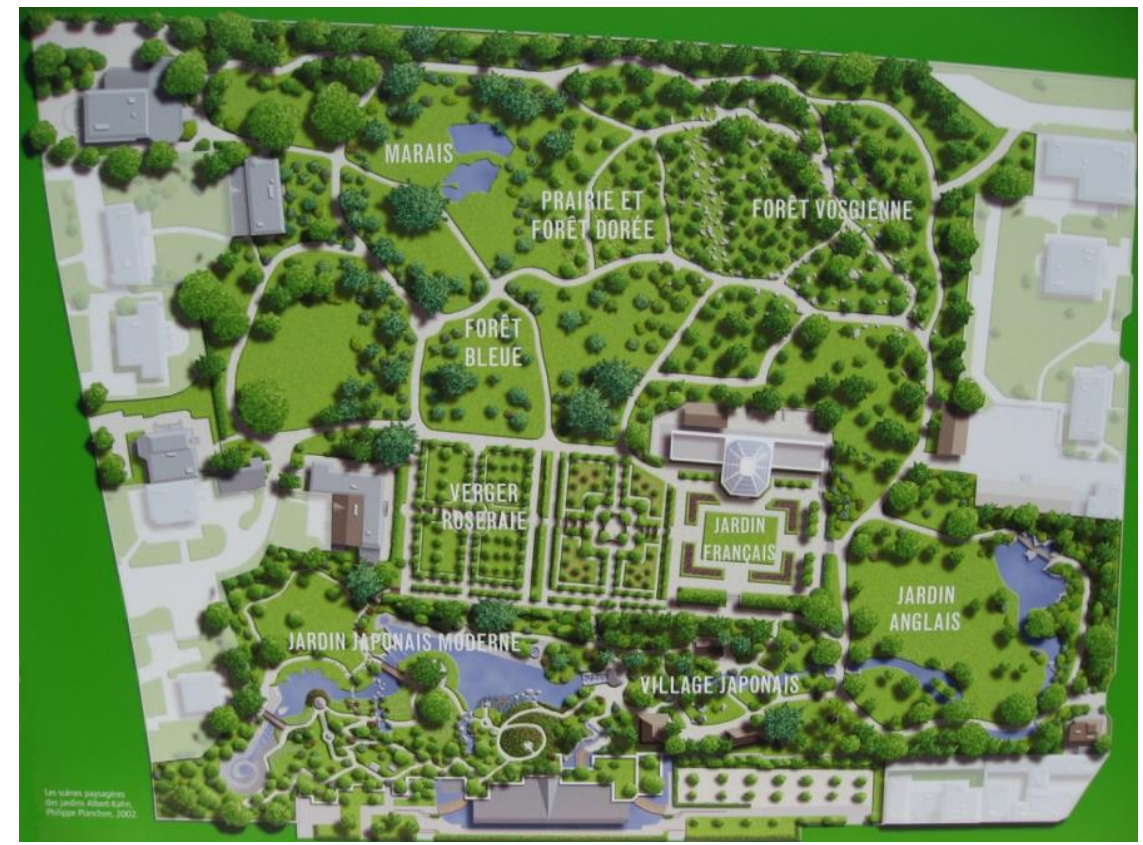

Fig. 4. Plano en relieve de la disposición del dominio Albert Kahn. (Fuente: https://commons.wikimedia.org/wiki/File:Jardin_du_Mus\%C3\%A9e_Albert -Kahn.Plan_02_by_Line1.jpg) (@Public Domain).

\footnotetext{
${ }^{12}$ Colegio de arquitectos de Barcelona. Conferencia "La arquitectura Japonesa y su fusión con la naturaleza". En el japonés antiguo, "ma" originalmente significa "espacio entre cosas que existen una cerca de la otra; es el intersticio entre ellas (...) En un contexto temporal es el tiempo o la pausa que ocurre entre un fenómeno y otro". Literalmente "Ma" significa "entre". Existe "Ma" entre personas, entre momentos y entre espacios.
} 
Para este arquitecto japonés, la arquitectura tiene como base la elección de los materiales, las formas derivarán de sus cualidades y de la relación con el entorno: en este caso, el pabellón de entrada ha de exhibir la naturaleza tecnológica del aluminio hacia el exterior y la madera en el interior y en la zona de relación con los jardines que estarán cercanos a la zona dedicada a las casas japonesas. El edificio de acceso se ha de ubicar en el solar que correspondía a los edificios ajenos al conjunto que ocupaban la esquina de la Rue du Port y hoy han desaparecido para dar espacio al nuevo edificio, sin que se toque el conjunto de la finca de A. Kahn.

Como hemos mencionado, para Kengo Kuma el material es el elemento fundamental en arquitectura. Más importante que espacios o formas. Cuando diseña un edificio busca provocar experiencias intensas, por lo que suele concentrar la utilización de materiales reduciéndolos al menor número. Le interesa el dominio de un material, al que le saca la mayor capacidad expresiva, eligiendo aquel que considera más acorde con el entorno "no me interesa contrastar con el medio ambiente, me interesa que se funda con él" (Zabalbeascoa, 2009), hay que escuchar a la cultura autóctona, y lo hace desde el valor estructural y no por el valor superficial o textural que el material pueda aportar. Por supuesto, no utiliza recubrimientos, sino que expone los materiales estructurales a la vista. Para él recubrir o forrar es "falsificar" (Ibidem). Ciertamente trabajar con materiales macizos, en vez de con revestimientos, encarece la obra, pero también pueden aligerarse. Entiende que pueda trabajarse con hormigón para reforzar los aspectos estructurales del edificio, pero considera los materiales como la piedra aligerada y la madera como materiales más acordes con el hombre. Esto no quiere decir que no experimente con otros materiales y saque grandes resultados de ello. El revestimiento metálico de la fachada del pabellón de acogida del museo es leído por los vecinos como una alusión al pasado tecnológico de la ciudad.

Le gusta experimentar con los materiales, rompiendo las formas. "La mitad de la arquitectura moderna son cajas: grandes y pequeñas. Si lo que la gente busca es una escultura, una caja puede llegar a serlo. Pero yo no quiero hacer esculturas en las ciudades. Me interesa más hacer agujeros: un patio, una terraza o un porche. Los agujeros invitan a entrar" (ibídem). Su arquitectura busca establecer un diálogo entre el material, el espacio, la luz y la forma para conseguir la disolución de la obra en el paisaje. 

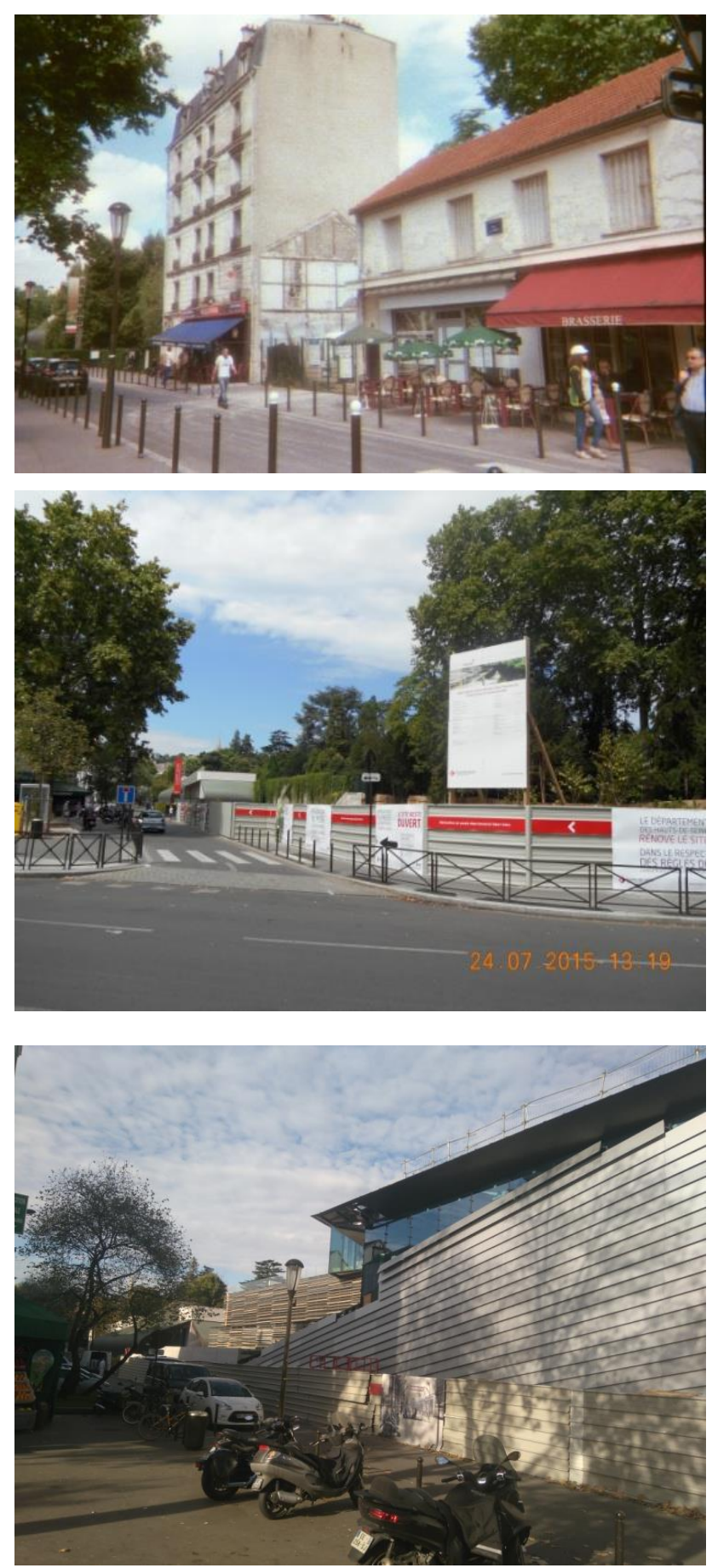

Fig. 5. Edificios hoy desaparecidos de la Rue du Port. Al fondo, entrada al Museo Albert Kahn. 2014. (Fuente: P. Aumente).

Fig. 6. Espacio liberado tras el derribo de los antiguos edificios de la Rue du Port para la construcción del nuevo pabellón de entrada al Museo Albert Kahn, 2015 (Fuente: P. Aumente).

Fig. 7. Estado actual (2017) de la construcción del pabellón de acogida del Museo Albert Kahn diseñado por Kengo Kuma. Rue du Port. (Fuente: P. Aumente). 


\subsection{Las Casas Japonesas y otras intervenciones.}

No se ha localizado documentación sobre el origen del hecho de la localización de estas casas japonesas en la finca de Albert Kahn. Se sabe el especial interés del mecenas por la cultura de Japón y la fuerte relación del banquero con la élite de la sociedad japonesa. Se dice que fue el apoyo de la banca Kahn a la compra de títulos del estado japonés durante la guerra con Rusia y la extensión por recomendación del banquero a colegas y figuras económicas a la absorción de dichos títulos, lo que predispuso a la sociedad japonesa a la simpatía por el francés. Esto apoyaría la tesis de que las casas pudieran ser un regalo.

El «village japonais» está constituido por el conjunto de tres edificaciones, la ubicada de forma aislada es conocida como la casa de thé; era una pequeña construcción, sobreelevada en una plataforma, quizá para evocar las edificaciones en las que tienen lugar estas ceremonias, y fue reconstruida en mayor tamaño en la actualización que se llevó a cabo en 1966.

Las llamadas casas japonesas son las dos edificaciones más valoradas del conjunto del legado. La actualización de estas dos construcciones exigía la restauración de los dos edificios y para ello, bajo la dirección de los arquitectos franceses Guy Latour, Agnès Latour y Jean Sebastien Cluzel, se constituyó un grupo de trabajo de reconocidos astesanos, maestros especialistas en la madera de costrucciones históricas, en el cual se incluyó a un europeo formado en Japón. La minuciosa restauración ha supuesto el recambio de las piezas de madera, una a una, y su montaje, exactamente igual que estaba. La sustitución de materiales es imperativa en Japón en las construcciones populares, el periodo de renovación debe ser de entre 20 a 30 años para garantizar la integridad de la edificación ${ }^{13}$. El proceso de restauración ha permitido saber que las casas se construyeron «in situ», es decir, que no fueron casas extraidas del contexto japonés en que se encontraban y reimplantadas en la finca de Kahn, sino construidas en la finca de Boulogne por un maestro carpintero denominado Suzuki,

\footnotetext{
1324 de julio de 2015. Dans la culture japonaise, on hiérarchise trois styles différents selon le «shin-gyo-so». Shin est le style le plus formel, à la recherche fidèle de la tradition stricte, placé le plus haut, alors que de gyo à so, on se permet de plus en plus de liberté....Ils auraient donc dû être conçus dans le style gyo, shoin-zukuri des habitations normales. Or ce n'est pas le cas, ils présentent un style mixte, et cette incohérence paraît étrange à ceux qui sont habitués à voir les maisons traditionnelles japonaises.

(http://www.e-bb.fr/pavillons-japonais-albert-kahn-46403/nggallery/page/3).
} 
que según evalua el equipo actual, pertenecía a la élite del oficio, el cual al construirlas creó una especie de síntesis de este tipo de construcciones populares, puesto que estas casas del Albert Kahn no siguen patrones de construcción características de una sola tipología de edificaciones japonesas. La falta de coherencia en el diseño lo avala, según afirma el maestro director del equipo de restauración. La intervención en el village japonés ha finalizado en 2016.

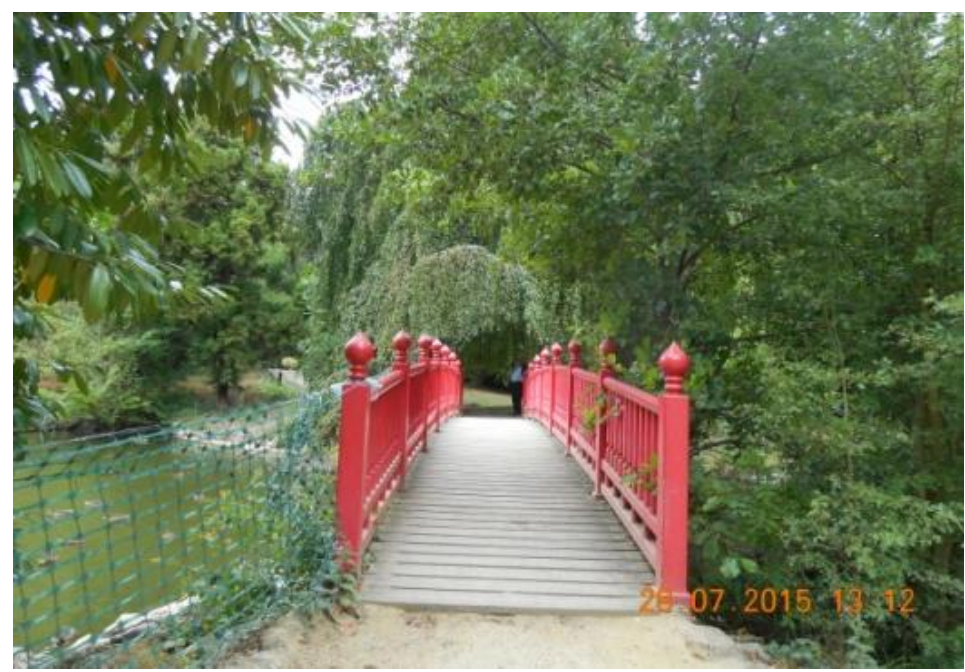

Fig. 8. Puente en el jardín japonés (2015) (Fuente: P. Aumente).

El proyecto general de intervención en la entidad contempla mejoras en todos los edificios en adecuación de los servicios y actualización de los recursos de presentación de los valores patrimoniales, incluidos los referidos a los Archives, y afectando también a la forêt Vosgiana, al Palmarium y las alas laterales de los invernaderos, que se van a destinar a comprensión del legado, por lo que deben adaptarse.

El jardín patrimonial ha sufrido algunas pequeñas alteraciones a lo largo del tiempo desde su fundación ${ }^{14}$ (introducción de algunas pequeñas áreas de

\footnotetext{
${ }^{14}$ El jardín fue concepción personal de Albert Kahn, pero con la colaboración valiosa del paisajista Achile Duchene quien fue llamado a diseñar en 1895 las distintas facetas o escenas del jardín. Su estilo clásico encaja perfectamente en el jardín francés, que expone su estilo heredero del de Le Nôtre tan querido en las cercanías de París, al que rinde homenaje en varios aspectos, incluidas las broderies sobre el tapiz geométrico que estuvieron instaladas delante del invernadero. Un jardín protector en invierno.
} 
juegos para niños durante un tiempo), pero fue la sección mejor comprendida del conjunto del legado, y permaneció largos periodos abierta al publico. La voluntad enciclopédica de Kahn se concentró en las seis escenas o áreas temáticas que aún hoy se conservan: el jardín japonés, su más querido rincón, creado a la vuelta de su viaje (la actual versión es de 1988), al que abría que añadir el sector de las casas japonesas, el jardín francés, el jardín inglés, la rosaleda, el bosque azul, con un pequeño lago pantanoso (el marais) en la prolongación al límite más al norte del conjunto de la finca, el bosque dorado, y el conjunto de la forêt Vosgienne ${ }^{15}$. Tras las obras la nueva presentación paisajística corre a cargo de Michel Desvigne, quien ha colaborado en otros tratamientos paisajistas de la renovación urbana de Boulogne-Billancourt ${ }^{16}$. Hoy es el arquitecto paisajista que ha diseñado el tratamiento de los espacios del polo cultural de la punta amont de la île Seguin en el marco del proyecto promovido por los Fondos de la Fundación Emerige. El objetivo de su intervención en la nueva presentación del Museo y Jardines A. Kahn es la de respetar y revitalizar lo que existe ya, hacer un trabajo muy discreto, así como hacer po-

${ }^{15} \mathrm{La}$ variedad de especies vegetales que ambientan las escenas paisasjistas del conjunto del jardín de Kahn aseguran el interés durante todas las estaciones. En este caso, la pradera de césped, los juncos, los narcisos y los arbustos que la bordean junto a los naranjos, los arces, los tilos o los lilos armonizan los colores en el pequeño vallecito del jardín inglés ambientado con el pequeño cottage que en la nueva presentación queda casi medianero con el nuevo pabellón de acogida rompiendo un poco el efecto de aislamiento que proporcionaban los plátanos que le aislaban del entorno urbano que apenas a unos metros amenaza su sosiego. La utilización del curso de agua así como la del cemento y la piedra imitando efectos rústicos, unido a la fábrica del cottage le otorgan el aspecto pintoresco, que era mayor en época de Kahn. Una pequeña construcción evocaba una lechería y junto a un pequeño palomar hacían pensar en las granjas inglesas (normandas) que parece ser que le atraían mucho. Una gran polifonía cromática se percibe en otoño en este jardín.

${ }^{16}$ Entre otras actuaciones ha realizado dos hectáreas de jardín efímero de prefiguración de lo que será el jardín central del Île Seguin. Este jardín se divide en tres grandes sectores, el jardín pedagógico en el que se conviven plantas viváceas, gramíneas y aromáticas; el jardín primario (con Salix de varios tipos: vitaminalis, alba. Caprea), y el jardín secundario: (cereales y cultivos). En este jardín trabaja el equipo con el arquitecto Inessa Hansch, quien ha diseñado los módulos y el mobiliario realizado en madera con un acabado en resina amarillenta. Desvigne, Premio Nacional de Urbanismo de Francia, ha trabajado también con Nouvel en diversos proyectos de los desarrollados y propuestos en Boulogne y con los arquitectos que a su vez han presentado alguna iniciativa en la ciudad; así mismo con Foster, Piano y Kuma, entre otros. http://micheldesvignepaysagiste.com/en/jardins-albert-kahn. 
sible que los nuevos espacios recuperados para el recorrido histórico y el entorno del nuevo pabellón ayuden a la potenciación de esos elementos, armonizando con ellos. Así, al integrarse al recorrido general tanto el Palmarium, como el Jardín de Invierno y el bosque Vosgiano (que se va a convertir en un espacio de interpretación del patrimonio vegetal), las conexiones con el recorrido se harán a través del enlace paisajístico. En el caso del Palmarium, que tenía una zona trasera muy hormigonada -en la cual se enclavaron hasta tres pequeños edificios auxiliares, dos de ellos hace tiempo desaparecidos- sí se actuará para ampliar la forêt vosgoniana.

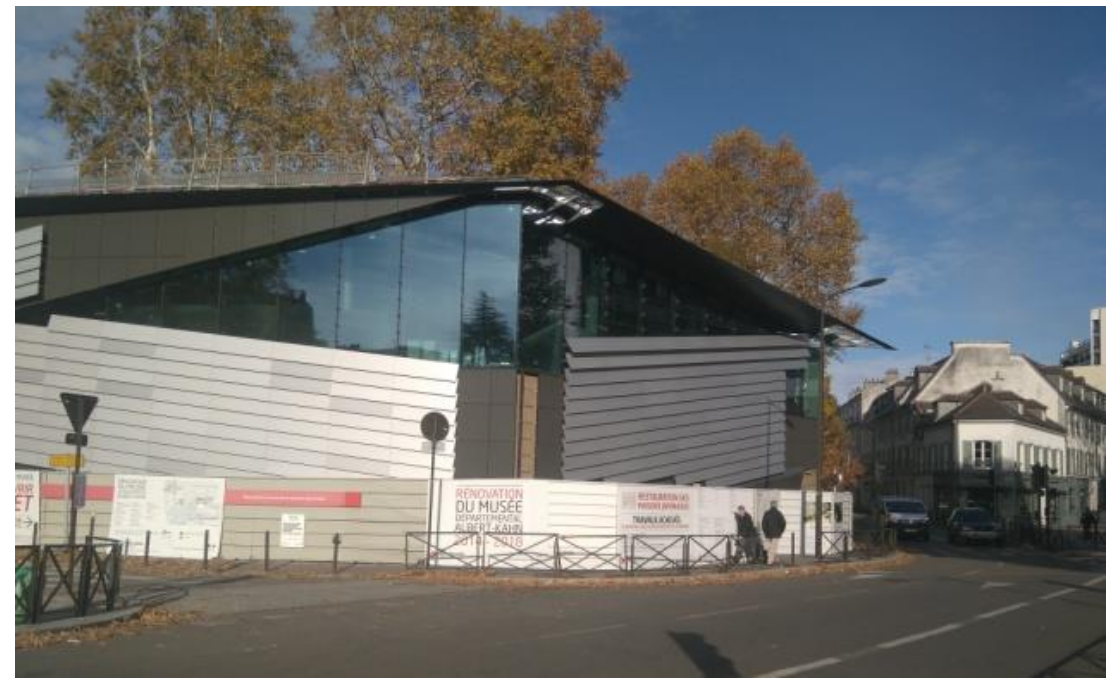

Fig. 9. Fachada a la Avenue Jean Baptiste Clement del Pabellón de acogida del Museo Albert Kahn. Arquitecto, Kengo Kuma. Estado actual (2017)

(Fuente: P. Aumente).

Ahora bien, la actualización del conjunto excede el ámbito arquitectónico y paisajístico, por lo que se ha estado atento al mantenimiento y potenciación de los medios de comunicación y las nuevas tecnologías que desde la propia institución colaboren en el conocimiento del museo. La página web ha ido completándose y sobre todo ha apostado por el dispositivo de geolocalización y el enlace con el sistema Open Data del Depatamento de Hauts de Seine ${ }^{17}$, para el mejor conocimiento de Les Archives de la Planète. La busqueda del documento fotográfico

${ }^{17}$ https://opendata.hauts-de-seine.fr/explore/dataset/archives-de-la-planete/?disjunctive.operateur 
o filmico, acompañado de noticias documentales que tienden a complementar el conocimiento y a fecha de hoy, salvo algunos errores de ubicación de conjuntos de fotografías situados en lugares que no les corresponden, ofrece una muy buena panorámica de lo que la colección es y las instalaciones pueden llegar a ser.

\subsection{La actualizacion del Musèe Departamental Albert Kahn como factor de distrito cultural.}

El conjunto patrimonial que contiene las valiosas colecciones fotográficas y fílmicas de carácter pionero reunidas por el humanista que dedicó su fortuna y su vida a poner en pie un proyecto científico y cultural de dimensiones enciclopédicas, está asentado en un dominio departamental incardinado en un "jardín de escenas"18 creado para permitir visualizar el concepto de diálogo de las culturas a través de la presentación y el cuidado conjunto de flores y plantas características de distintas culturas del mundo. Varios edificios instalados en los límites de los jardines que sirvieron de sede a bastantes de los proyectos y actividades desarrolladas en el ámbito cultural que Kahn forjó, así como diversas construcciones, derivadas de las diversas presentaciones temáticas de los mismos, constituyen el conjunto. Las condiciones museísticas que un museo actual requiere han impulsado al Departamento de Hauts de Seine a abordar un amplio proyecto de renovación que no solo actualice el museo, sino que sirva de estímulo para reactivarle en el seno de una ambiciosa operación distral que tiene la cultura como motor económico de primer orden.

El grueso del proyecto de renovación se vuelca sobre la mejor acogida del público, teniendo en cuenta criterios museológicos actuales, de ahí el interés puesto en el edificio de acogida, puesto que el objetivo de la intervención es la captación de un segmento fundamentalmente turístico ${ }^{19}$ : “Un des enjeux de cette rénovation est de redonner une visibilité au fonds patrimonial d'AlbertKahn et de toucher un public le plus large et le plus nombreux possible ${ }^{20}$.

\footnotetext{
$18 \mathrm{http} / / /$ albert-kahn.hauts-de-seine.fr/jardins/les-differents-jardins/jardin-anglais/

${ }^{19}$ La banlieue chic de l'Ouest parisien. Entre mémoire industrielle, nouvelles formes de tourisme portées par les habitants et récit de la modernité. https://teoros.revues.org/2780?lang=en 34, 1-2 | 2015: Le tourisme hors des sentiers battus.

${ }^{20} \mathrm{http}$ ://www.e-bb.fr/renovation-du-musee-jardin-albert-kahn-le-projet-laureat-29258/. Patrick Devejian en el acto de presentación de la maqueta del proyecto de renovación planteada por Kengo Kuma.
} 
La cité de la Musique y el Museo-Jardines Albert Kahn, ya ha suscitado críticas de historiadores del arte que han manifestado su malestar por el sesgo comercial de la operación ${ }^{21}$. Sin embargo, el planteamiento es coherente con la tendencia económica actual. Ese es el sustrato que impulsa el proyecto institucional de erigir La Cité de la Musique y el conjunto de Les Archives de la Planète y Musèe-Jardins A. Kahn en imágenes referenciales de la Vallée de la Culture (Hauts de Seine).

En efecto, en 2008, Patrick Devedjian Presidente del Departamento Hauts de Seine $(2008)^{22}$, pone en marcha una plataforma diseñada para impulsar el territorio al que pertenece la ciudad de Boulogne Billancourt, y todos sus enclaves. El objetivo de esta estructura era «créer une continuité avec la capitale» (Daniel Janicot), en beneficio de la consecución del Gran Paris y el esplendor de Île de France. Con ella se pretende definir un recorrido aguas abajo de los límites de la Villa de París con el río como eje, tal y como en la ciudad de París ya viene establecido, lo que supone visibilizar puntos fuertes culturales en ambas márgenes, iniciando el recorrido con la Tour aux figures de Dubufett en la Isla de Saint Germain, teniendo como corazón a l'Île Seguin, además de otros hitos culturales de Boulogne Billancourt y enlazando con seleccionados legados culturales del resto de communes ribereños hasta culminar en la Défense. En la ribera derecha del Sena, nos encontramos el quartier transformado por una gran operación immobiliaria, denominado Le Trapèze (antigua sede industrial Renault en Billancourt), que una vez arrasado, ha quedado convertido en un hábitat altamente tecnológico que se desea ver prolongado hasta el puente, por lo que se ha terminado de renovar el "quartier du Pont de Sévrès". Hacia el noreste se prevé visibilizar más intensamente los valores patrimoniales contenidos en el Museo de los Años Treinta, instalado en el ala este del Espacio Landowsky, junto a la Mairie, y en el límite de la actual renovación urbana que se ha desarrollado en el entorno del centro administrativo que diseñó Morizet en los años treinta, así como la potenciación del Chateau Buchillot, en donde se ha decidido presentar en conjunto la obra escultórica

\footnotetext{
${ }^{21}$ Roland Recht, professeur au Collège de France. Journal des Arts no 270, noviembre, 2007. https://1895.revues.org/2752\#tocto1n5.

${ }^{22}$ Tras las elecciones de 2008 se crea la Agencia para la Vallée de la Culture. Se instituye bajo el amparo del Estado y la colaboración del Departamento de Hauts de Seine, y la Ville de Boulogne Billancourt.
} 
de Paul Belmondo contextualizada con obras de sus contemporáneos. El eje se completa con los hitos culturales de la ribera izquierda.

La creación de este "Vallée de la Culture", viene ya inspirada en la determinación del Estado de crear un eje de carácter distral a lo largo del Sena, que enlazará con otros ejes para mayor gloria de París. En efecto, tras acceder a la Presidencia del Gobierno de Francia en 2007, y hasta 2012, Nicolás Sarkozy va a laborar por la irradiación de París en la Región para lo cual impulsa el antiguo proyecto del Gran París. En el centro de la nueva gran metrópolis se dibujaba un eje en torno al Sena en el que se destacaba la creación en Île Seguin de un núcleo cultural dedicado a todas las artes:

En el corazón de la metrópolis se verá el Valle del Sena transformarse en Valle de la Cultura. En el centro La Gran Biblioteca, el Gran Louvre, Orsay, El Museo de las Primeras Artes, El Grand Palais renovado, La Cité de l'Architetture y una nueva Institución autónoma emblemática dedicada al arte contemporáneo, instalada en el Palais de Tokyo. Al oeste en el Bois de Boulogne la Fondation Louis Vuitton para la creation e Îlle Seguin dedié a tous les arts, cuya forma urbana será ella misma un monumento ${ }^{23}$.

Desde la presidencia del Gobierno se impulsó (2009) un concurso de ideas para Île Seguin en el que participó Jean Nouvel que acudió en compañía de Jean-Marie Duthilleul y Michel Cantal-Dupart. Los Ateliers Nouvel se encargaron finalmente de realizar proyectos arquitectónico-urbaníticos para la Isla, que no fueron realizados. Hoy día Laurent Dumas, con el respaldo de la potente firma immobiliaria Emerige, impulsa el proyecto cultural de la punta

\footnotetext{
${ }^{23}$ Discurso de N. Sarkozy en la Cité de l'Árchitecture et de Patrimoine, 9 de abril de 2009. Se ha planificado que La Île Seguin asuma una concentración de instituciones culturales que colmaten la isla, en la que se ha arrasado cualquier resto o testimonio de la existencia previa de la localización in situ de las Usines Renault, salvo pequeños testimonios de no interferencia a la colonización urbanística: arco de entrada a las fábricas, zócalo, puentes de acceso y poco más, como ocurre, igualmente, en el quartier de Le Trapèze. Dos grandes polos culturales, cada uno en una punta de la isla, se diseñan como locomotoras económicas para la mejora de la ciudad y el territorio. La Cité de la Musique en la pointe aval y el R4. La Cité de la Musique ya está acabada, y lo que se preveía como el R4, no realizado, (la villa artística concebida por Nelly Wenger y a la que los Ateliers Nouvel proyectaron en su forma arquitectónico-urbanística), ha sido sustituido, después de muchos avatares y tras la adquisición de las acciones por parte de Laurent Dumas, conocido mecenas y presidente de la empresa immobiliaria Emerige, por un nuevo proyecto.
} 
amont de la Isla bajo la batuta arquitectónica y artística de Baumshlager Eberle en colaboración con RCR Arquitectes.

La entidad cultural La Vallée de la Culture, se organiza con lógica distral24. surge por decisión política y se estructura es agrupación de entidades culturales que se complementan, con la finalidad de dar impulso económico y urbano al eje territorial en que se inscribe, con la voluntad de seguimiento a la iniciativa de los ejes marcados por la presidencia del gobierno, en la conciencia de la importancia del impulso que supone la cultura para la mejora de la atractividad de un territorio ${ }^{25}$. En la actualidad, el Departamento hace énfasis en la importancia de sus dos sedes culturales punteras en BoulogneBillancourt: La Cité de la Musique (Île Seguin) y más al norte, el hoy renovado Museo-Jardín Departamental Albert Kahn.

\section{Bibliografía.}

AMAD, Paula (2001): “Cinema's sanctuary': From pre-documentary to documentary film in Albert Kahn's Archives de la Planète (1908-1931)", in Film History, vol. 13, no 2 .

AumenTE, Pilar (2011): “Fotografía y Arquitectura. Un marco histórico". En Chaves, M. A. Fernando García Mercadal. Arquitectura y Fotografía. MadridSegovia, Universidad Complutense de Madrid y Demarcación de Segovia del Colegio Oficial de Arquitectura de Castilla y León Este.

BRUNHES, Jean: Autour du monde, regards d'un géographel regards de la géographie. Boulogne: Musée Albert Kahn, 1993.

BRUNHES, Jean (1914) : La géographie de l'histoire. Introduction à la seconde année du cours de Géographie Humaine (College de France, 1913-1914, in Revue de Geographie annuelle, VIII, fasc. 1, Paris, Delagrave.

${ }^{24}$ El distrito cultural es una construcción intencional de agentes políticos que consideran el patrimonio cultural como eje estratégico de un nuevo modelo de desarrollo (Preite, 1998; Ferilli y Sacco, 2011: 30).

25 “Hoy, y todos los estudios lo demuestran, la atractividad -comprendida en ella la económicade los territorios pasa por la cultura. Es en este espíritu que hemos lanzado en 2008 nuestro proyecto del Valle de la Cultura" (Patrick Devedjian). Declaración de P. Devejian en la presentación del número extraordinario que la revista La Vallée de la culture dedicó a la conmemoración de los 50 años de la fundación del Departamento de Hauts de Seine. La Vallée de la culture. La revue culturell du Conseil Général des Hauts de Seine. Été 2014, pág. 3. 
CASTO, Teresa (2008): “Les Archives de la Planète et les rythmes de l'Histoire", 1895. Mille huit cent quatre-vingt-quinze [En ligne], 54 | 2008, mis en ligne le 01 février 2011 (https://1895.revues.org/2752\#tocto1n1-n2).

COEURE, Sophie (1996): “Albert Kahn, observateur de la planète. Les crises économiques du 20e siècle" In: Vingtième Siècle, revue d'histoire, n 52, octobre-décembre 1996., p. 141-143.

Coeuré, S. (1996): “Albert Kahn observateur de la Planète". Revue d'Histoire vingtième siècle p. 143 http://www.persee.fr/docAsPDF/xxs_02941759_1996_num_52_1_3579.pdf

DeVedjIAN, Patrck (2014): La Vallée de la culture. La revue culturell du Conseil Général des Hauts de Seine. Été.

KAHN, Albert (1860-1940). Réalités d'une utopie (Boulogne: Musée Albert Kahn, 1995).

KAHN, Albert. (1918): Des droits et des devoirs des gouvernements.

KuMA, Kengo (2009): Entrevista con Kengo Kuma. Edic. impresa de "El País", de 29 de agosto de 2009.

LAVÉDRINE, Bertrand y GANDOLFO, Jean Paul (2009). L'autocrome Lumière. Secrets d'atelier et défis industriels. París, CTHS.

LUSSAULT, Miche (2005): "Les territoires urbaines en quête d'image" Urbanisme. Les chemins de la democratie .mai- jun 2005, $n^{-}$342, en MONGIN, Olivier. "Quelle reconfiguration territoriale? ¿Quelle reconfiguration democratique?". Les chantiers du Grand Paris.

OKuefunA, David (2008): The wonderful world of Albert Kahn. Colour photographs from a lost age. BBC Books.

RECHT, Roland (2007) : Journal des Arts nº 270, nov.

ZabalbeascoA, A. (2009): “Kengo Kuma, el arquitecto matérico". Babelia, El País, 29/08/2009. [en línea: http://elpais.com/diario/2009/08/29/babelia/ 1251500767_850215.html].

\section{Url.}

http://albert-kahn.hauts-de-seine.fr/albert-kahn/fondations/

http://www. autochromes.culture.fr/index.php?id=90\&L=0

http://albert-kahn.hauts-de-seine.fr/ 
http://albert-kahn.hauts-de-seine.fr/archives-de-la-planete/lescollaborateurs/jean-brunhes/

http://www.persee.fr/docAsPDF/xxs_02941759_1996_num_52_1_3579.pdf

http://www.engawa.es/index.php?/projects/--la-tension-del-vacio----------/

http://kkaa.co.jp/works/architecture/albert-kahn-musee-et-jardins/

https://teoros.revues.org/2780?lang=en 34, 1-2 | 2015: Le tourisme hors des sentiers battus

http://www.e-bb.fr/renovation-du-musee-jardin-albert-kahn-le-projet-laureat29258/

https://opendata.hauts-de-seine.fr/explore/dataset/archives-de-laplanete/?disjunctive.operateur

https://1895.revues.org/2752\#tocto1n5

http://www.ejumpcut.org/archive/jc48.2006/KahnAtlas/Atlas2.html 